\title{
DISCUSIÓN CRÍTICA ACERCA DE LOS PRINCIPIOS QUE INSPIRAN LA SUPUESTA NECESIDAD Y LEGITIMIDAD DEL MEJORAMIENTO HUMANO
}

\author{
José Domingo Vilaplana Guerrero \\ Huelva
}

Resumen: La pretendida aceptación entusiasta del proyecto transhumanista que parece dominar buena parte del ámbito filosófico y tecno-científico más influyente y mejor dotado de medios para su desarrollo y ejecución no puede ser neutralizada desde dentro del paradigma que lo ha visto y hecho nacer. Tal es el paradigma materialista-fisicalista-mecanicista, un paradigma esencialmente causalista, geométrico, determinista y reduccionista que o bien niega la existencia de lo que no puede explicar, o bien lo reduce a partes elementales, igualmente desconocidas, pero obediente metodológicamente al dogma del análisis, la síntesis y la medida.

Palabras clave: Transhumanismo, mejoramiento humano, paradigma materialista-mecanicista, legitimidad moral, modelos comprensivos alternativos.

Critical essay on the principles which inspire the assumed need for human enhancement and its legitimacy

Abstract: The allegedly enthusiastic acceptance of the transhumanist project which seems to dominate the most influential and best endowed philosophical and techno-scientific scope cannot be neutralised from within the paradigm which has brought it into life. This is the materialistic-physicalist-mechanistic paradigm; in essence, a causalistic, geometric, deterministic and reductionist paradigm which either rejects the existence of what cannot be explained or reduces it to elemental parts, equally unkown, but which, from a methodological point of view, complies with the principles of analysis, synthesis and measurement.

Keywords: transhumanism, human enhancement, materialistic-mechanistic paradigm, moral legitimacy, alternative comprehensive models.

Recibido: 20/09/2018 Aprobado: 20/02/2019

Naturaleza y Libertad. Número 12, 2019. ISSN: 2254-9668 
José Domingo Vilaplana

Deliberadamente, el título de mi ponencia presenta la serie de conceptos imprecisos y ambiguos que el propio programa transhumanista necesita gestionar para seguir avanzando en su progresiva e irreversible ejecución. Es más, lo que de filosófico tiene tal programa, aparte de sus facetas científica, tecnológica y político-social, reclama desde sí un debate de esta naturaleza, quiero decir desde la orilla filosófica, para de este modo dejar claras y manifiestas las cartas que manejan sus críticos, y para que queden bien dibujados y delimitados los bandos en contienda, explicitando precisamente los principios que a cada uno inspiran. Se trata de una corriente filosófica, el transhumanismo, ciertamente en boga, rehén de lo que Feyerabend llama la "adicción tecnológica", que no es más que la expresión actual de otras adicciones más sutilmente contraídas y de las que me ocuparé más adelante. Pero de momento lo que quiero manifestar es que fomentar o alimentar el debate crítico desde los mismos predios transhumanistas acerca de su legitimidad y necesidad juega subrepticiamente al juego del destape doctrinal, a sabiendas de que cualquier expresión crítica contraria al dogma que inspira la corriente transhumanista será tachado de retrógrado, anacrónico, y sus postulantes serán objeto de exclusión académica, burlas ridiculizantes o, como puede estar llegando a suceder, prisión preventiva en las cárceles del anonimato y la inanición presupuestaria. En la medida que este foro no se configura con otra voluntad sino la de entender el fenómeno y compartir la preocupación intelectual, filosófica y ética, antropológica en definitiva, por los riesgos para la Humanidad que su realización pudiera llevar asociados, es por lo que creo que puedo manifestar sin ambages mi posición al respecto, que deberá ser expuesta con claridad, precisión y brevedad a partes iguales. Veamos.

Las expresiones « "principios", "necesidad", "legitimidad" y "mejoramiento humano" — perverso eufemismo— que jalonan el título de mi ponencia son claves, pues marcan o demarcan desde dentro el ámbito de la 
discusión al tiempo que introducen el suficiente grado de edulcorante léxico como para no despertar mayores reticencias entre el público poco avisado. El adalid del transhumanismo invita, pues, al crítico, más bien lo desafía, a que niegue los "principios", una vez identificados, es decir los sustituya por otros y demuestre que los suyos son mejores; le sugiere que neutralice la "necesidad", es decir proponga otra necesidad diferente o en sentido contrario o diverso, conducente a un escenario atópico distinto, y mejor; también lo reta a que cuestione la "legitimidad", o sea explique qué es lo auténticamente legítimo para él, apoyado en esos otros principios conducentes a esa otra versión de la humanidad futura; y finalmente, le insta a que ose sospechar del hecho indubitable y casi sacralizado de que el ser humano es manifiestamente "mejorable" y, consiguientemente, es legítimo mejorarlo si ello está en nuestras manos (es decir en manos de los técnicos especialistas, o que en tales se erijan, que no es lo mismo que "en nuestras manos"). Bien, en este momento hago explícita mi tesis de fondo: La pretendida aceptación entusiasta del proyecto transhumanista que parece dominar buena parte del ámbito filosófico y tecno-científico más influyente y mejor dotado de medios para su desarrollo y ejecución no puede ser neutralizada desde dentro del paradigma que lo ha visto y hecho nacer. Tal es el paradigma materialista-fisicalista-mecanicista, un paradigma esencialmente causalista, geométrico, determinista y reduccionista que o bien niega la existencia de lo que no puede explicar, o bien lo reduce a partes elementales, igualmente desconocidas, pero obediente metodológicamente al dogma del análisis, la síntesis y la medida, aunque en la práctica todo ello naufrague en un mar de incógnitas, unas matemáticas, otras empíricas, pero serán sus incógnitas, las legítimas, siempre despejables y solubles, y no las ajenas, mistéricas, nacidas de la ignorancia científica o del oscurantismo religioso, o de ambas formas lamentables de vida intelectual.

De este modo, ya no resulta sorprendente leer de un filósofo la siguiente afirmación: 
José Domingo Vilaplana

Aclaro desde ahora que creo que el transhumanismo tiene razón al proclamar que el ser humano es una entidad manifiestamente mejorable, no sólo desde el punto de vista físico, sino también desde el psicológico, el cognitivo, el moral, el emocional..., y que la tecnología puede proporcionar muchas de las mejoras que necesita (Diéguez, 2017: 30).

Es decir, pareciera estar fuera de toda duda (ni metódica ni escéptica) el hecho de que el ser humano como especie, y cada ser humano como miembro de ella, necesita ser mejorado por ser, no ya imperfecto, sino perfectible y, consiguientemente, "incompleto" (cuidado con esta palabra, de resonancias heideggerianas, kierkegaardianas y singularmente orteguianas, que últimamente se ha convertido en asidero desde el que mirar con cierta indulgencia los desafueros transhumanistas); susceptible, pues, de ser mejorado no de un modo meramete terapéutico, esto es: paliativo, sino estructural, a nivel de diseño. Así podrá llegar el día en que se imponga un nuevo diseño de brazo que suplante al que traemos de fábrica, y quizá sea obligatorio amputarlo para sustituirlo por otro mejor, sopena de quedar KO en los primeros embites en la lucha por la vida, dígase por el éxito profesional, la eficacia social, el bienestar personal... O llegará el momento en que se implanten potenciadores de memoria o supresores de penas —esas rémoras debilitantes - que del mismo modo mejorarán manifiestamente las vidas individuales y sociales de estos seres sufrientes y maltrechos, tan vulnerables desde antes incluso de nacer..., pero ya muy muy cercanos —ya se atisba la nueva alborada que soñamos desde hace más de tres siglos- a la felicidad y a la inmortalidad gracias... igracias a sí mismos!, pues, contra todo pronóstico, han logrado sobreponerse a sus carencias originarias y a su condenado destino de enfermedad, dolor y muerte. ¿Cómo es posible, no obstante, que seres tan defectuosos hasta el extremo de sufrir, morir y gozar por nimiedades supersticiosas puedan llegar a ser capaces de dar un salto cualitativo en su propia configuración como para elevarse a un plano evolutivo nuevo, marcado por un progreso tecno-científico ilimitado e ilimitadamente meliorativo? En realidad, esta pregunta, incómoda para el 
modelo antropológico transhumanista, pone de manifiesto un grado de complejidad del ser humano incompatible con el paradigma dominante en la tecno-ciencia actual, esa que investiga en robótica, en inteligencia artificial, en biología molecular, o en biotecnología médica, que son las fuentes desde las que se prodiga el ciego entusiasmo que a todos de un modo u otro nos condiciona y nos domina, pero que se ha convertido en el nuevo objeto de culto religioso. Así el ser humano rinde culto a sí mismo a través de unos productos que para salvarlo lo niegan y lo reconfiguran.

Es curioso este fenómeno, sobre todo por lo que tiene de contradictorio. Para el paradigma fisicalista mecanicista el ser humano, como todo ser vivo, es un constructo cuyas piezas elementales son inertes; el hecho de estar vivo es, en definitiva, un modo de hablar, porque en rigor científico no sabemos que la vida sea otra cosa que un fenómeno circunstancial, azaroso, una feliz — por decir algo amable- coincidencia de fuerzas electromagnéticas y asociaciones elementales de una materia en vías de ser conocida (aunque resulte que cada vez lo es menos), regida por leyes inmutables (inmutabilidad hoy abiertamente cuestionada, véase Sheldrake), si bien tampoco plenamente conocidas (a pesar de los problemas que el ajuste fino plantea a los apóstoles del ciego azar). Por no ser conocidas plenamente es por lo que desconocemos el origen de la arquitectura vital desde lo no vivo, pero nadie desde la más estricta ortodoxia científica se atreve a cuestionar que el origen de la vida pueda o deba ser otro que desde la no-vida de los materiales orgánicos e inorgánicos básicos. Desde esta perspectiva, somos, por tanto, sí, zombies; qué de extraño tiene. Es decir, somo seres que nos llamamos "vivos" y "humanos" pero cuya constitución y funciones, cuyas características emocionales, subjetivas e identitarias no son otra cosa que emergencias reductibles a procesos y entidades elementales, simples en cierto modo, como se espera que indudablemente la ciencia suprema pondrá de manifiesto (indubitabilidad a costa de podar todo lo que estorba, siguiendo el método canonizado de comenzar el edificio del conocimiento desde abajo, es decir desde el origen y desde los elementos esenciales, como si de componer un sistema desde sus unidades constituyentes se tratara, 
José Domingo Vilaplana

negando además cualquier atisbo teleológico, inteligente y aún menos teológico, en cualquier versión). Por eso es un reto, lo fue para Touring y lo sigue siendo para la vanguardia en robótica y en inteligencia artificial, lograr el diseño de una máquina cuyas respuestas interactivas sean indiscernibles de las respuestas que pudiera dar un humano, hombre o mujer, no importa, porque tampoco en ello hay diferencias cuando el mecanismo se desguaza en sus componentes primarios. Pues eso que llamamos humano en realidad no es más que una manera de hablar, de señalar, como decir gallina o tulipán; algo que debe ser perfecta y artificialmente replicable, imitable hasta lograr la plena asimilación simétrica y solapable con la máquina, y consiguientemente mejorable, como lo es cualquier máquina. Cabe la posibilidad, no obstante (y esto cuando lo estudié me resultó conmovedor), como sugieren Eudald Carbonell y Robert Sala en su libro Aún no somos humanos. Propuestas de humanización para el tercer milenio (Carbonell/Sala, 2003), que esto a lo que llamamos "humano" aún no lo sea, y que sólo devendrá en tal cuando logre superar su condición primate, que lo mantiene anclado a una genética de instintos animales, jerarquizantes, violentos, dominantes..., brutos, en definitiva. ¿Cómo superar entonces esa condición animal que nos confiera la plena humanidad? Nada más sencillo, qué pregunta: mediante la técnica, en progreso irreversible y transformador, y su delicado proceso de socialización — responden. Transcribo uno de los pasajes más delirantes de la obra citada:

La socialización de la ciencia, iniciada tímidamente en el siglo XVII, muy avanzada en el siglo XX y necesitada de un desarrollo decidido en el futuro, junto con la socialización de la enseñanza, un progreso exclusivo del siglo $\mathrm{XX}$, puede conseguir definitivamente abrir las puertas al futuro, en libertad y una vez que hayamos liminado la intromisión de la jerarquía religiosa y el dictado del dogma como fuente de pensamiento. No como fuente de conocimiento, porque únicamente la ciencia ha sido capaz de llegar al verdadero conocimiento. (Carbonell/Sala, 2003: 172-3) 
Como vemos, no hay que recurrir necesariamente a Dawkins cuando se trata de identificar a algún prócer del sectarismo cientifista. Pero lo que me lleva a transcribir el texto anterior es su carácter ejemplar de lo que sin reticencias y desde un terreno más científicamente riguroso que el de la paleoantropología, investigadores y pensadores como Rupert Sheldrake, Terrence Deacon, Paul Feyerabend, David Bohm o Juan Arnau cuestionan, a saber: no sólo el paradigma fisicalista mecanicista, newtoniano en definitiva, que domina la ortodoxia científica (a pesar del anonadante buceo a través de la nada y la incertidumbre en que tanto la mecánica cuántica como la relatividad general parecen estar sumidas), sino la versión destilada y sugestiva del mismo que se ha apoderado de la mentalidad del hombre occidental, señor del planeta, de sus recursos (herencia baconiana) y del universo entero, que pretende colonizar en un futuro cada vez más cercano. Si cabe considerar alguna alternativa a este dominio desnortado que hace pasar por el ojo estrecho de un embudo todo lo que aspire a ser considerado realidad, conocimiento y verdad, y por tanto la única opción legitimada para programar la senda evolutiva de los hombres y del medio en el que habita, quizá deba atenderse a, o atrevernos a mirar por, algunas de las ventanas (Bohm) que abren estos adalides silenciados y perseguidos por haber cometido el pecado mortal de la herejía. Su sano escepticismo, su atrevimiento a mirar desde otro ángulo y no dejarse someter a ese lavado de cerebro que sufre el investigador, a decir de Feyerabend, además de su audacia para imaginar nuevas narraciones en que la comprensión prime sobre el mito de la explicación y de la búsqueda de los orígenes, metáfora de la concepción reduccionista propia del materialismo..., hace que la lectura de obras como El espejismo de la ciencia (Sheldrake), La conquista de la abundancia y Tratado contra el método (Feyerabend), La totalidad y el orden implicado (Bohm) o La fuga de Dios (Arnau), entre otras, nos convenzan de que el transhumanismo, en cualquiera de sus versiones (cultural o tecnocientífica, y sus múltiples variantes: tecnológico o biomédico, terapéutico o meliorativo, etc., pero todas comunicadas por el mismo concepto de hombre: un ser fallido que ha tenido la fortuna, quizá inmerecida, de estar en disposición de enmendarse 
José Domingo Vilaplana

a sí mismo, de autodesasnarse, digamos), es la consecuencia natural del dominio absoluto de un paradigma científico, absolutizado bajo la noción suprema de Ciencia, elevada al rango de nueva y única religión verdadera, con su hermetismo esotérico, su lenguaje cifrado, su inaccesibilidad pública y sus jerarquías de poder no necesariamente al servicio del conocimiento y del bien humanos, vicaría por la que todos terminaremos pasando antes o después, de manera fatal e irreversible, porque todos, sin excepción, queremos recobrar la salud y, por qué no, querremos ser más fuertes, más atractivos, más inteligentes, más sanos indefinidamente y, si fuera posible, ya puestos, inmortales, salvo decisión propia o accidente (ivaya por Dios!). Si la conquista de todo esto se vende como un logro al alcance de la mano, y esto lo defiende con matices muy livianos alguien tan elegante y moderado como Antonio Diéguez, pero que lo pregonan con soberbio entusiasmo por todos los medios de comunicación del mundo occidentalizado Marvin Minski (ya fallecido, pero eficaz activista por la causa mientras vivió), Ray Kurzweil o el venezolano José Luis Cordeiro (véase La muerte de la muerte, 2018), ¿quién debidamente esclavizado al dominio tecnológico y biomédico se negaría o rechazaría tan evidentes mejoras? Contra esta dependencia esclavizante se manifiesta Feyerabend con su habitual contundencia entre bronca y genial:

...yo recomiendo situar la ciencia en su lugar, como una interesante pero de ninguna manera exclusiva forma de conocimiento que tiene muchas ventajas pero también muchos inconvenientes. [...] para mí el chauvinismo de la ciencia es un problema mucho mayor que el problema de la corrupción intelectual y aquél tal vez sea una de las principales causas de este último. Los científicos no están contentos en moverse por su delimitado terreno de juego de acuerdo con lo que ellos consideran que son las reglas del método científico, sino que desean universalizar estas reglas, desean que formen parte de la sociedad en general y para conseguir sus propósitos emplean todos los medios disponibles: argumentos, propaganda, tácticas de presión, intimidación, cabildeos. (Feyerabend, 1981: 211) 
Denuncia Feyerabend precisamente la desnudez del rey, el barro mortal del que también los científicos están hechos, y la propia ciencia, a pesar del temor reverencial que provoca su figura exultante e inexpugnable, logia donde moran la objetividad y la verdad, y desde donde se decide qué es real, por tanto de donde también emanan el deber moral y el bien común. Sheldrake no le va a la zaga en esta línea y denuncia igualmente la visión idealizada de la ciencia, de la ciencia materialista, que proclaman y difunden personajes tan influyentes como el polifacético showman británico Ricky Gervais, incluido en 2010 por la revista Time en el catálogo de las cien personas más influyentes del mundo (que ya es decir para un showman), cuya capacidad de llegar al gran público y de influir en él es abrumadora. El propio Sheldrake acota algunas de las píldora con que Gervais difunde el trabajo científico, algo que podrían suscribir en nuestro país muchos periodistas que ungidos por un afán divulgador y educativo, y con la mejor intención pero desde una inocencia propia de doctos ignorantes, practican de hecho un culto casi religioso a la ciencia y a los científicos en sus programas de radio o televisión o en las revistas de divulgación científica que dirigen, como Ángel Expósito, en un espacio de su programa vespertino, el programa A hombros de gigantes, de RNE, Eduardo Punset, durante años en su programa Redes, o Jorge Alcalde, director de la revista Quo. Dice Gervais:

La ciencia busca la verdad. Y no discrimina. Para bien o para mal descubre las cosas. La ciencia es humilde. Sabe lo sabe y sabe lo que no sabe. Basa sus conclusiones y creencias en evidencias sólidas —evidencias constantemente actualizadas y mejoradas- . No se ofende cuando surgen nuevos hechos. Abraza el cuerpo del conocimiento. No se apega a las prácticas medievales porque formen parte de la tradición. (Sheldrake, 2018: 43)

Quizá eso debiera ser la ciencia y así de santos deberían ser los científicos, pero no es así. Lo grave de esta creencia sin matices y perfectamente desinformada de cómo funciona la investigación científica y qué intereses hoy la sostienen, es que, como dice Sheldrake, "Para los creyentes en la 
José Domingo Vilaplana

'perspectiva científica', todo lo que necesitamos es aumentar la comprensión pública de la ciencia a través de la educación y los medios”. Y continúa: "Desde el siglo XIX, la creencia en el materialismo se ha propagado con notable éxito: millones de personas se han convertido a este punto de vista 'científico', aun cuando saben muy poco de ciencia. Son devotos de la Iglesia de la Ciencia, o cientificismo, de la que los científicos son sacerdotes" (Sheldrake, 2018: 42). Sheldrake está convencido, y en sus obras deja plena y argumentada constancia de ello, de que "las ciencias, a pesar de su éxito, están ahogadas por creencias obsoletas". Lo trágico es que esas ciencias, marcadas por su materialismo irrefutable, quiero decir blindado, aparte de obsoleto, están conduciendo al ser humano precisamente a una asfixia por ahogamiento, por falta de oxigenación que lo libere de la cárcel en la que ha quedado confinada su imaginación y su capacidad de participación, eludiendo la formación crítica que demandan Sheldrake o Feyerabend: una formación auténticamente multidisciplinar que otorgue capacidad para decidir consciente y fundadamente a qué saber consagrar su vida el investigador o el profesional, es decir a qué ciencia conformar su mente, sabiendo que es una más, con su propio léxico, sus propias reglas y su propio discurso narrativo, que si tiene talento podrá hacer progresar, pero nunca en la línea de absolutizar ni su narración ni su verdad. El transhumanismo es la manifestación de la intoxicación materialista, vencedora sobre el animismo, el vitalismo o cualquier forma de organicismo. Vencedora por motivos de inercias y jerarquías, por motivos ideológicos y económicos, no porque no vayan apareciendo nuevas vías de exploración y de comprensión, como las que desde diversos ámbitos, dentro de la órbita científica, van forjando el propio Sheldrake, Terrence Deacon, Owen Barfield o David Bohm, ya nombrados la mayoría, en gran medida inspirados en una corriente de pensamiento claramente marginada a pesar de su enorme potencial que va desde Berkeley, Goethe o William James hasta Bergson o Whitehead, entre otros, pasando por las desconocidas y despreciadas filosofías orientales.

No es momento, y ya voy terminando, por la obligada brevedad de esta exposición, de desgranar en detalle y valorar el alcance de las propuestas 
comprensivas y narrativas de estos científicos y pensadores heterodoxos, pero estoy persuadido de que sólo profundizando en esas posiciones alternativas y su capacidad desmitificadora del paradigma dominante (agotado en la teoría, pero no en la práctica, que es la que manda) podría cuestionarse de raíz la propuesta transhumanista y sus postulados de fondo. Los tres postulados de fondo que inspiran el transhumanismo, nacidos de una concepción azarosa de la vida y de su visión del hombre (a lo que ya me he referido), así como la legitimidad moral que le asiste, son, expuestos muy resumidamente, los siguientes: 1 . No hay ninguna propiedad específica de los seres humanos que haya que proteger o salvaguardar (materialismo radical); 2. Las posibles consecuencias negativas que puedan traer las aplicaciones tecnobiológicas son todas susceptibles de corrección a medida que el conocimiento progrese (fe ciega en la verdad del conocimiento científico, y por tanto en su carácter salvífico); 3. Dada la inevitabilidad del progreso científico, el mejoramiento moral será igualmente necesario e inevitable (mejoramiento integral del ser humano como deber moral). Desde estas perspectivas no hay opción: el ser humano está llamado a trascenderse a sí mismo, y ello, en la medida en que viene propiciado por un progreso real, ha de ser necesariamente bueno.

Estos postulados: "materialismo radical", "fe ciega en el conocimiento científico", auspiciado por el dominio absoluto del paradigma causalistanewtoniano, y el "deber moral e inexcusable del mejoramiento humano", son las líneas de flotación contra las que Sheldrake lanza su crítica a los dogmas y creencias de la ciencia, así como su discusión sobre el principio de legalidad inmutable y absoluta que inspira la investigación científica, condición de la visión causalista mecanicista que domina la tecnociencia. Por su parte, Terrence Deacon (Naturaleza incompleta, 2011) indaga sobre la influencia de lo ausente sobre lo presente, y lo hace desde el campo de las neurociencias, comprendiendo el carácter inmaterial de los significados y su extraordinaria influencia sobre el mundo, tendiendo así un puente muy valioso desde el punto de vista heurístico entre el mundo de las ciencias y el de las humanidades. Habla Deacon de "causalidad entencional", noción que 
José Domingo Vilaplana

integra lo intencional (mental) y lo funcional (biológico), agrupando los propósitos mentales con las funciones orgánicas. Afirma Deacon: "La causalidad entencional aparece como una suerte de magia, al menos desde el punto de vista puramente fisicoquímico, porque supone la influencia de algo que no está presente" (Arnau, 2017: 129), intencionalidad que la ciencia oficial ha decidido negar con toda la contumacia que su dogmatismo le permite. A su vez, Paul Feyerabend invita a desconfiar de aquellos que apelan a lo racional, porque no pretenden otra cosa que imponer su propio vocabulario; también invita a desconfiar de los que apelan a los "hechos", porque, dice, están defendiendo su laboratorio particular. Pero aparte de su crítica al método científico, algo que afirma no se practica (y sí un lavado de cerebro de los estudiantes e investigadores que sólo ven con las anteojeras -léase vocabulario y rutinas incuestinables- que les implantan en su periodo de formación básica), algo que afortunadamente se infringe constantemente, porque sólo así puede progresar la ciencia, propone Feyerabend una separación radical entre ciencia y Estado, es decir entre ciencia y poder e intereses económicos, desde una concepción de la ciencia más cercana a una colección de historias, de narraciones, que de un modelo epistemológico. Si en cierto modo esta visión se hubiera difundido en los medios educativos y formativos no se habría incurrido en su ideologización, que tan malos augurios parece anticipar. Se pregunta Feyerabend:

¿No es posible que la ciencia, tal y como la conocmos hoy, o la "búsqueda de la verdad" al estilo de la filosofía tradicional, cree un monstruo? ¿No es acaso posible que cause daño al hombre, que haga de él un mecanismo miserable, hostil, convencido de que es mejor que los otros, un mecanismo sin encanto y sin humor? (Feyerabend, 1981)

Quizá uno de esos mostruos sea la propuesta transhumanista, anclada en una visión mecanicista, es decir fragmentada de la realidad, de cualquier realidad. Esta concepción fragmentada de lo real está siendo contestada desde mediados del siglo pasado, y desde el ámbito de la física cuántica, por 
investigadores como David Bohm. Su teoría del "orden implicado" concibe la totalidad como un orden plegado; se trata de un orden más profundo donde las cosas, que no son independientes sino sólo vistas a cierta escala, como ya intuyó Whitehead, enraizan, es decir están íntimamente vinculadas; de ese orden derivan tanto las nociones de espacio y tiempo como las partículas materiales. En el seno de ese orden "mundo material" y "conciencia" están implicados, coimplicados. El observador y lo observado están entrelazados, en el experimento se encuentra el experimentador. No hay pues medidas absolutas, no hay objetividad absoluta porque es imposible una plena externalidad del sujeto respecto de los objetos. Cosmos y conciencia aparecen así como una totalidad no fragmentada y en movimiento (Arnau, 2017). El transhumanismo se muestra, desde esta perspectiva holística, como una forzada y violenta separación del sujeto humano respecto del cosmos en el que está integrado, formando parte activa y no fragmentada del mismo. Nada bueno puede traernos esa terrible amputación de nuestra conciencia, de nuestra más íntima subjetividad, que es parte del cosmos.

En la misma estela de Bohm encontramos a Owen Barfield (Salvar las apariencias, 2015), para quien existe un vínculo extrasensorial entre el percipiente y las representaciones, de ahí su noción de "participación". Los fenómenos mismos son diferentes para cada "testigo >, si bien estos pueden compartirlos — ver, sentir, oler... lo mismo - en la medida en que compartan educación, lenguaje y la experiencia de lo cotidiano, tres formas de lo colectivo que orientan a la propia experiencia y a la relación con el mundo. Romper esa integración mediante la imposición de un modelo representacional unívoco y supuestamente universal y verdadero, como el 
José Domingo Vilaplana

transhumanismo y sus ya apreciables manifestaciones en las sociedades actuales (uniformidad tecnológica y de género ${ }^{1}$ ) establecen, supone, contra lo acríticamente admitido, todo lo contrario de un progreso en la profundización de nuestra humanidad, sino el mayor de los atentados que la soberbia humana y su idiocia endiosada pudiera llegar a cometer contra sí misma.

¿Hacia dónde vamos? ¿Sigue dependiendo de nosotros mismos rectificar el camino? Mucho me temo que ya no seamos "nosotros mismos": individuos conscientes de sus decisiones cooperativas, responsables de ellas y con capacidad para rectificar, sino el rebaño, confundido y cada vez mejor amaestrado, que pastorea una élite —aleación de ciencia, poder y dineropoderosísima, ensoberbecida y manifiestamente incómoda con su propia humanidad, de la que reniega, y que irreversiblemente nos conduce al abismo ignoto y helado que esta loca fantasía compartida dibuja como la auténtica y definitiva Arcadia.

\section{Bibliografía}

J. Arnau, La fuga de Dios. Las ciencias y otras narraciones, Girona, Atalanta, 2017.

O. Barfield, Salvar las apariencias, Girona, Atalanta, 2015.

D. Bohm, La totalidad y el orden implicado, Barcelona, Kairós, 2014.

${ }^{1}$ Sobre el vínculo entre Transhumanismo e Ideología de género ya he tratado en otro lugar ["¿'Tienen sexo lo masculino y lo femenino? Indicios transhumanistas en la ideología de género" (Colegio de Médicos de Sevilla, abril, 2018). Conferencia inédita]. La ideología de género aprovecha la debilidad del paradigma mecanicista, que asocia con la defensa de un esencialismo inaceptable, para descargar su crítica contra la ciencia y su ingenua pretensión de verdad. Sin embargo, la misma ideología de género, que pasa por ser una forma del transhumanismo cultural, termina reclamando la versión tecnocientífica y biomédica del transhumanismo precisamente para trascender lo que entiende como limitación del sexo, origen de todas las diferencias, o sea de todas las injusticias, y así o "decidirlo", como mal menor, o anularlo en la figura transhumana del ciborg. 
E. Carbonell / R. Sala, Aún no somos humanos. Propuestas de humanización para el tercer milenio, Barcelona, Quinteto, 2003.

J. L. Cordeiro / D. Wood, La muerte de la muerte, Barcelona, Deusto, 2018.

A. Diéguez, La vida bajo escrutinio. Una introducción a la filosofía de la biología, España, Biblioteca Buridán, 2012

-Transhumanismo. La búsqueda tecnológica del mejoramiento humano, Barcelona, Herder, 20017.

P. Feyerabend, Tratado contra el método, Madrid, Tecnos, 1981.

- La conquista de la abundancia, Barcelona, Paidós Básica, 2000.

N.Y. Harari, Homo deus, Barcelona, Debate, 2017.

R. Sheldrake, El espejismo de la ciencia, Barcelona, Kairós, 2012.

José Domingo Vilaplana Guerrero jdomingov@hotmail.com 